\title{
Status of a Marginal Dugong (Dugong Dugon) Population in the Lagoon of Mayotte (Mozambique Channel), in the Western Indian Ocean
}

\author{
Jeremy Kiszka', 2, 3, Catharine Muir ${ }^{4} \&$ Alban Jamon ${ }^{1}$ \\ ${ }^{1}$ Past affiliation: Observatoire des Mammifères Marins. Office National de la Chasse et de la Faune Sauvage, \\ Direction de l'Agriculture et de la Forêt. BP 103, F-97600 Mamoudzou, Mayotte (France); ${ }^{2}$ CRELA (Centre \\ de Recherche sur les Ecosystèmes Littoraux Anthropisés), UMR 6217, CNRS-IFREMER-Université de La \\ Rochelle, Avenue Michel Crépeau, F-17071, La Rochelle, France; ${ }^{3}$ Direction de l'Environnement et du \\ Développement Durable, Collectivité Départementale de Mayotte. BP 101 F-97600 Mamoudzou, Mayotte; \\ ${ }^{4}$ Sea Sense, P O Box 105044, Dar es Salaam, Tanzania
}

Key words: Dugong, Dugong dugon, Mayotte, status, distribution, conservation

\begin{abstract}
The dugong (Dugong dugon) is one of the most endangered mammal species in eastern Africa. Dugongs are exposed to many human-induced threats, such as by-catch in fishing gears and deliberate killing. In order to understand the conservation and management issues surrounding this species status assessments are needed. An assessment was conducted in Mayotte (Comoros, Mozambique Channel) in 2003 to determine the status and distribution of the dugong. Questionnaire surveys were carried out in August 2003 with local fishermen. Results of opportunistic sightings were collected from 1999 to 2005 ( $n=53)$, and aerial surveys were undertaken between July and November 2005. The three data sources provide historical and actual data on the status of the species. Dugongs were common in the lagoon before the 1980 's, and then declined significantly due to hunting pressure and by-catch in fishing nets. In the 2000's, opportunistic sightings have been made regularly by recreational dive operators and microlight aircraft pilots. Recent sightings indicate calving in the lagoon of Mayotte, with several observations of mother-calf pairs. Measures to protect Mayotte's marine biodiversity, such as establishing a network of Marine Protected Areas, banning fishing nets and developing pelagic fisheries is expected to help ensure the future survival of the dugong in this area.
\end{abstract}

\section{INTRODUCTION}

The dugong (Dugong dugon Müller 1776) is the only herbivorous mammal that is strictly marine and is the only member of the family Dugongidae. It is the most abundant sirenian, and occurs in the waters of at least 48 countries and territories of the Indo-Pacific region from east Africa to Vanuatu, between $26^{\circ}$ and $27^{\circ}$ north and south of the equator (Marsh, pers. comm. 2007; Nishiwaki \& Marsh, 1985; Marsh et al., 2002). The eastern Africa coast/western Indian Ocean region is the western boundary of the dugong's global range. Here, they occur in small numbers off Somalia, Kenya, Tanzania and Mozambique as well as off the islands of the Seychelles, Comoros, Madagascar, and Mayotte (Marsh et al., 2002; WWF EAME, 2004). The dugong population in this region is severely depleted due to incidental catch and to direct take, and their future survival is uncertain (Marsh et al., 2002; WWF EAME, 2004). In Mayotte, as in the other states of the western Indian Ocean (including Madagascar), the status and distribution of dugongs is poorly known and data 
on abundance and the level of impact from human activities (such as incidental and deliberate catches) are lacking. In order to determine the distribution and conservation status of dugongs in the lagoon of Mayotte, questionnaire surveys, combined with the collation of opportunistic sightings and the conduction of an aerial dedicated survey, have been conducted.

\section{MATERIALS AND METHODS}

\section{Study area}

Mayotte $\left(45^{\circ} 10^{\prime} \mathrm{E}, 12^{\circ} 50^{\prime} \mathrm{S}\right)$ is situated in the northern Mozambique Channel, between Madagascar and the African mainland, and is part of the Comoros archipelago (Figure 1a). Mayotte is almost entirely surrounded by a $197 \mathrm{~km}$ long barrier reef, with a second double-barrier in the southwest and the immerged reef complex of Iris, in the northwest, which has an area of $40 \mathrm{~km}^{2}$. There are a series of deep passes through the reefs, some of which are the sites of old rivers (Quod et al., 2000). The inner

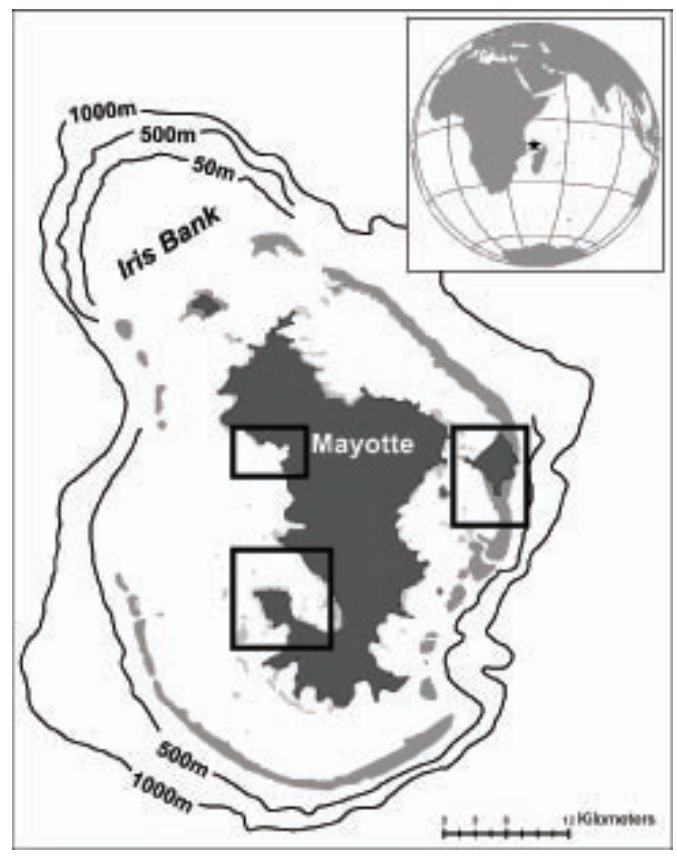

Fig. 1a. Location of the study area with physical characteristics of the lagoon of Mayotte and adjacent slope waters and locations of areas where fishermen encountered dugongs lagoon has an area of $1,200 \mathrm{~km}^{2}$ with an average depth of $20 \mathrm{~m}$, but reaches maximum depth of $80 \mathrm{~m}$ in the west. The main island is surrounded by a fringing reef $(195 \mathrm{~km})$, which is discontinuous where there are river mouths. In 2005, a seagrass habitat assessment was conducted (Loricourt, 2005). 11 species were recorded, including those documented as preferred by dugongs such as Halophila, Halodule, Cymodocea and Thallasia (Marsh et al., 1982; André et al., 2005).

\section{Data collection}

Structured questionnaire interviews were conducted singly in August 2003, with 35 local fishermen from 6 villages located in the north of Mayotte, on Île de Pamandzi, and in the west (Figure 1b). The reliability of respondents was not formally tested, however, respondents were asked to identify a dugong from a selection of marine mammal photos. Questions included number and location of sightings, group characteristics (size, presence of calves), population trends and threats. Opportunistic dugong sightings were collected from whale/dolphin watching operators, and recreational diving and aircraft operators. On several occasions, photos were provided to confirm the identification of dugongs.

Aerial surveys are the most suitable technique to estimate distribution and abundance of dugongs and such population assessments have been performed through aerial surveys throughout the dugong's range (Rathbun et al., 1988; de Iongh, 1995; Marsh, 1995; Hines et al., 2005). An ultra-light motorised aircraft (ULM, Petrel 912), with pilot and observer, flying at a constant speed of 45 knots and altitude of 1,000 feet, was used to assess the presence of dugong in the lagoon. Transects were conducted perpendicular to the coast, extending to the external slope waters of the barrier reef. Seagrass meadows, where dugongs were expected to be seen feeding, especially during ebb and high tides, were also explored.

\section{RESULTS}

From the thirty five questionnaire interviews conducted, all the respondents were male and ranged in age from 32 to 75 years. Seventy four percent of 


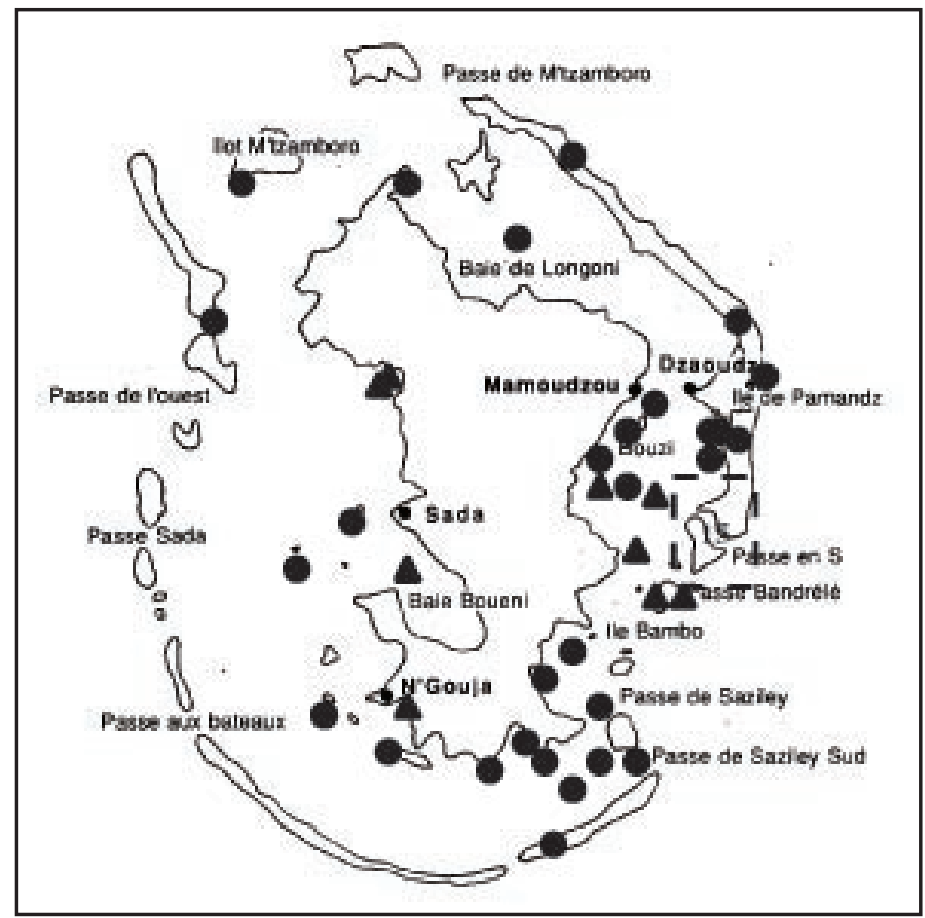

Fig. 1b. Spatial distribution of opportunistic sightings from 1999 to 2005 . Triangles represent mother-calf pairs or groups containing a mother-calf pair. Dots are singletons or groups of adults. The dotted line is the Passe en S area where multiple sightings were recorded $(n=15)$

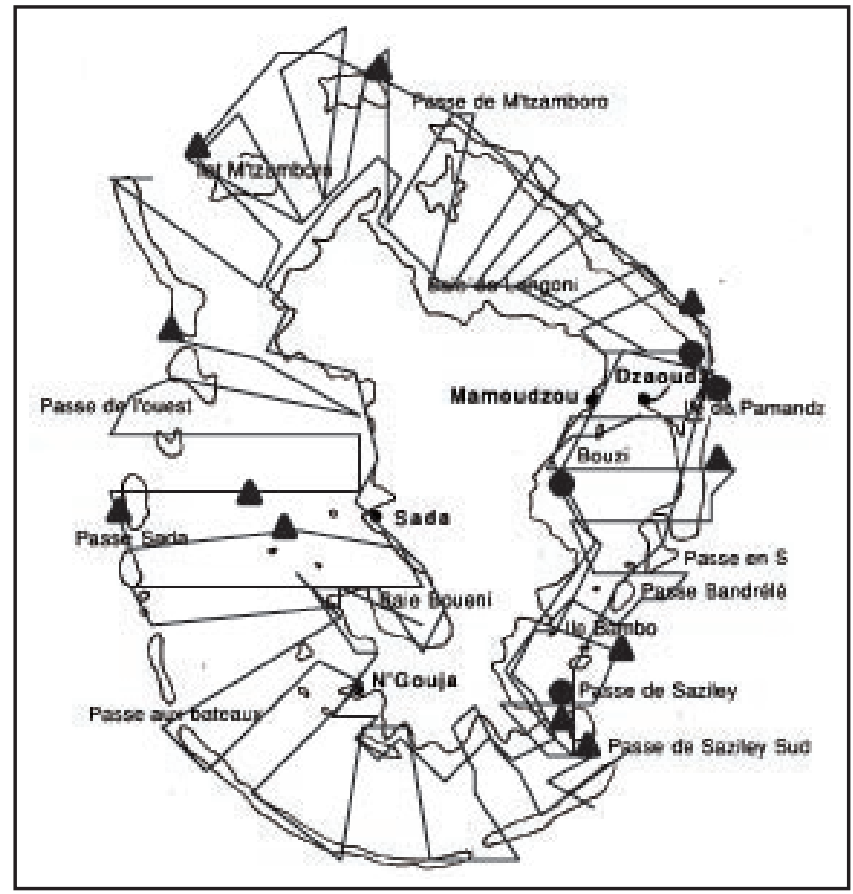

Fig. 1c. Effort coverage and marine mammal sightings (ots: dugong; triangles: cetaceans) during the exploratory aerial surveys from July to November 2005 
respondents had observed dugongs at least once, $3 \%$ recognised a dugong from the picture but had never seen one and $23 \%$ had never heard of a dugong. Of those who had seen a dugong, the number of sightings varied from one to seven (mean=2.2; mode $=1 ; \mathrm{sd}=1.74$ ). Respondents observed dugongs most frequently inside the lagoon. The areas where sightings of dugongs were most often reported were the Bay of Tsingoni, the Bay of Bouéni and the surrounding waters of Île de Pamandzi (Figure 1b). All fishermen using nets $(n=17)$ claimed that they had incidentally caught a dugong at least once during their career. Several fishermen admitted that when a dugong is caught alive in their nets, it is usually killed for its meat. The gear is a bottom set gillnet with a mesh size of 12 inches, usually placed above shallow coral reefs and in bays. When a fisherman catches a dugong in his net, the meat is consumed locally or sold directly on the beach or at the nearby market. The price per kilogramme of meat is between US\$2.5 - 6.5. Intentional hunting of dugongs occurred prior to the 1980's when the dugong population was larger. A respondent reported that in the Bay of Bambo there were so many dugongs that every week they were hunted from a small pirogue using a simple harpoon. Eight seven percent of the respondents claimed that direct take posed the greatest threat to dugongs before the 1980s but incidental net captures pose the greatest contemporary threat.

Ultra-light motorized, ULM $(\mathrm{n}=1)$ and dive $(n=6)$ operators collected the bulk of opportunistic sightings. In total, dugongs were sighted on 24 occasions between 2000 and 2003 (16 from the air and 8 by divers). A map on the spatial distribution of sightings is shown in Figure 2. Multiple sightings were made around Île de Pamandzi, in the Passe en $\mathrm{S}$ and in the wider eastern part of the lagoon (where most flights are made). All the sightings made by the dive operator were made in the Passe en S, the most important diving site in Mayotte.

Aerial surveys were conducted from the 17 July to 5 November 2005. The sea conditions were poor during flights in the southern lagoon, a portion of the western area as well as in the north, and $38 \%$ of the aerial survey effort was conducted in wind speeds greater than $20 \mathrm{~km} / \mathrm{h}$ which is close to the limit for such operations. A total of 21.4 hours were flown over the lagoon of Mayotte. Five dugongs were encountered (three single animals and a mother-calf pair), all in the eastern part of the lagoon (Figure 1c).

\section{DISCUSSION}

Most of the information on the status of the dugong in the lagoon of Mayotte is anecdotal. Nonetheless, this information, combined, provides an important basis from which to develop conservation and management plans. This assessment indicates that dugongs do still occur in Mayotte waters but historical data and recent sightings suggest that numbers are low. Historical data provided by local fishermen showed that dugongs were common in the lagoon of Mayotte before the 1980s. The decline of the population is probably the result of dedicated hunting pressure and incidental captures in gillnets. Fishermen reported that dugongs were distributed throughout the lagoon and were easy to see. The apparent changing status of dugongs around Mayotte is similar to other areas in eastern Africa, such as in Tanzania, Kenya and Madagascar (Marsh et al., 2002; WWF EAME, 2004). In these countries, the decline of dugong populations is also linked to deliberate killings as well as incidental gillnet captures. The aerial surveys, although limited by poor weather conditions, nonetheless confirmed the presence of dugongs and that calving still occurs in the waters around Mayotte.

These surveys cannot provide absolute abundance estimates, as the number of sightings were too low and there were no corrections for survey bias. Sightings were only made during calm days ( $<6 \mathrm{~km} / \mathrm{h}$ winds) such as in the eastern lagoon where sea conditions were very good. Additional aerial surveys are needed during optimal weather conditions to provide a better idea of the abundance of dugongs in the lagoon of Mayotte.

Sightings made by diver and micro-light aircraft operators as well as by various other observers were mostly from the eastern part of the lagoon, probably because most effort was concentrated in this area. Mother-calf pairs were recorded throughout the study period, including the dedicated surveys in 2005. These observations have provided evidence that calving still takes place in the lagoon of Mayotte, and that the small population is still breeding, though from the dataset established it is 
not possible to determine critical dugong areas, as sightings were so scarce.

The last incidental catches in bottom nets were reported in the south of Mayotte in September and July 2004 around Île de Pamandzi. Several threats facing dugongs have been identified in Mayotte mainly from interviews and from net captures. These include: incidental catches in fishing nets (mainly coastal gillnets), habitat destruction, pollution, disturbance and boat strikes. Urban areas in Mayotte are expanding and the human population is expected to double in 2010 (300,000 people; INSEE, personal communication). The level of pollution and habitat degradation is expected to rise accordingly. Although dugong captures are now rare, the threat is still likely to be significant in view of the small size of the resident population.

In Mayotte, various management strategies have been implemented by the local authorities, which are contributing to the conservation of dugongs. These include: banning, since 2004, the use of fishing nets over coral reefs and seagrass beds; the implementation of a network of Marine Protected Areas, including large seagrass areas where dugongs have been sighted; and the development of pelagic fisheries to relieve fishing pressure in the lagoon. As dugongs are mobile species (Sheppard et al., 2006), a regional approach to their conservation, including better knowledge of their distribution, abundance, population structure and movement patterns is needed. Such an approach would identify critical areas for dugong populations as well as their connectivity (e.g. migratory, genetic). Finally, restricting the use of gillnets throughout the dugong's range in the western Indian Ocean is needed, especially in critical areas where dugongs are known to occur (Marsh et al., 2002).

Acknowledgements - The authors would like to thank the following persons having contributed to this work: Robin Rolland (DAF), Franck Charlier (ONCFS), Bernard Rota (Globice Réunion), Mireille Quillard (CDM), Stéphane Ciccione (Kelonia), Pascal Hervé (Mayotte ULM), Olivier Abellard (DAF) and Jean-Benoît Nicet (DAF) and the following diving clubs for providing dugong sightings: Rêve Bleu, Aqua Diva, Maji Club, Nyamba Club, le Jardin Maoré and Lambis. Nils Bertrand (Sea Blue Safari) is also thanked for providing data, and the following surveyors for their dedication during questionnaire surveys: Ali Hamada, Mohamond Boina, Antoy Lahi Soilihi. We thank Peter Ersts (American Museum of Natural History, Center for Biodiversity and Conservation, NY) for providing the map of the study area and Pr. Helene Marsh for her valuable comments.

\section{REFERENCES}

André, J., Gyuris, E. \& Lawler, I. (2005). Comparisons of the diets of sympatric dugongs and green turtles on the Orman Reefs, Torres Strait, Australia. Wildl. Res. 32: 53-62.

de Iongh, H.H. (1995). Aerial surveys of the dugong (Dugong dugon, Müller 1776) in coastal waters of the Lease Islands, East Indonesia. Mar. Fresh. Res., 46: 759-761.

Hines, E.M., Adulyanukosol, K \& Duffus, D.A. (2005). Dugong (Dugong dugon) abundance along the Andaman coast of Thailand. Mar. Mam. Sci., 21: 536-549.

Loricourt, A. (2005). Étude des herbiers de phanérogames marines de Mayotte. Master Degree in Aquatic Ecosystem Dynamic. UPPE. $61 \mathrm{pp}$.

Marsh, H. (1995). Fixed-width aerial transects for determining dugong population sizes and distribution patterns. In T.J. O'Shea, B.B. Ackerman \& H.F. Percival (Eds). Population Biology of the Florida Manatee. Information and Technology Report 1, U.S. Department of the Interior, National Biological Service, Washington, DC. Pp. $56-62$

Marsh, H., Penrose, H., Eros, C. \& Hughes, J. (2002). Dugong: status report and action plans for countries and territories. Early Warning and Assessment Report Series. UNEP. 162 p.

Marsh, H., Channells, P.W., Heinsohn, G.E. \& Morrisey, J. (1982). Analysis of stomach content of dugongs from Queensland. Austr. Wild. Res., 9: 55-67.

Nishiwaki, M. \& Marsh, H. (1985). The dugong. In: S.H. Ridgway \& Harrisson R.J. (Eds). Handbook of Marine Mammals Vol. 3. Academic Press, London: 1-31.

Quod, J.P., Naim, O. \& Abdourazi, F. (2000). The Comoros archipelago. In: C. Sheppard (Ed.). Seas at the Millennium: an environmental evaluation. Pergamon Press, Oxford. Pp. 243-252.

Rathbun, G.B., Brownell, R.L., Ralls, K. \& Engbring, J. (1988). Status of dugongs in waters around Palau. Mar. Mam. Sci., 4: 265-270.

Sheppard, J.K., Preen, A.R., Marsh, H., Lawler, I.R., Whiting, S.D. \& Jones, R.E. (2006). Movement 
heterogeneity of dugongs, Dugong dugon (Müller) over large spatial scales. J. Exp. Mar. Biol. Ecol., 334: 64-83.

WWF EAME (2004). Towards a Western Indian Ocean Dugong Conservation Strategy: The Status of Dugongs in the Western Indian Ocean Region and Priority Conservation Actions. WWF Eastern African Marine Ecoregion, Dar es Salam, Tanzania. 68 pp. 